\title{
Network analysis after epigenome wide methylation study revealed JUP as a regulator of co-methylated risk-module for T2DM
}

Anil K Giri1, ${ }^{1,2}$, Gauri Prasad ${ }^{1,2}$, Vaisak Parekkat ${ }^{1}$, Donaka Rajashekar ${ }^{1}$, Nikhil Tandon ${ }^{3}$, Dwaipayan Bharadwaj2,\#4*

${ }^{1}$ Genomics and Molecular Medicine Unit, CSIR-Institute of Genomics and Integrative Biology,

New Delhi, India

${ }^{2}$ Academy of Scientific and Innovative Research (AcSIR), Ghaziabad, India.

${ }^{3}$ Department of Endocrinology and Metabolism, All India Institute of Medical Sciences, New

Delhi, India

${ }^{4}$ Systems Genomics Laboratory, School of Biotechnology, Jawaharlal Nehru University, New

Delhi, India

\#Current affiliation

*Correspondence to:

Prof. Dwaipayan Bharadwaj

Systems Genomics Laboratory

School of Biotechnology

Jawaharlal Nehru University

New Delhi 110067, India

Telephone: 011-2670 4089 \& 011-2674 2696

E-mail: db@jnu.ac.in db@mail.jnu.ac.in 


\begin{abstract}
:
Controlling the global Type 2 diabetes mellitus (T2DM) pandemic requires a better understanding of its risk factors across different populations, and needs markers that can precisely predict the individual risk to the disease. DNA methylation due to environmental factors is a known mechanism for conferring risk to T2DM. To identify such methylation signatures and associated risk to the disease, we performed an epigenome-wide-association study (EWAS) in 844 individuals of Indo-European origin. Within the Indian population, we identified and validated 6 novel differentially methylated $\mathrm{CpG}$ sites in PDCD6IP, MIR1287, 5S_rRNA, HDAC9, KCNK16, and RTN1 genes associated with T2DM risk at the epigenome-wide-significance-level $\left(\mathrm{p}<1.2 \times 10^{-7}\right)$. Further, we also replicated the association of 3 known CpG sites in TXNIP, SREBF1 and CPT1A in the Indian population. Using methylation-based-network analysis, we identified 4 comethylated modules, which we named as turquoise, yellow, brown, and blue, among differentially methylated $\mathrm{CpG}$ sites in discovery phase samples. We observed that methylation of the brown module with $28 \mathrm{CpG}$ sites, associated with T2DM risk factors (e.g., BMI, insulin, C-peptide). Upon further analysis, we noted that these methylation signatures at 14 of the brown module's CpG can be used as marker to segregate T2DM patients with good glycemic control (e.g., low HbAlc) but poor lipid profile (low HDL and high TG) from the other patients. Additionally, we discovered that rs6503650 in the JUP gene regulates methylation at all the 14 hub CpG sites of the brown modules as methQTL. Our network-assisted epigenome-wide association study is the first to systematically explore DNA methylations conferring risks to T2DM. In addition, the study shows the potential use of identified risk $\mathrm{CpG}$ sites for patient segregation with different clinical outcomes. These findings can be useful for better stratification of patient in order to improve the clinical management and treatment outcomes.
\end{abstract}




\section{Introduction:}

Type 2 diabetes mellitus (T2DM) is a causal factor for several micro- (e.g., retinopathy, nephropathy, neuropathy) and macro-vascular related complications (e.g., cardiovascular disorders) with nearly 4 million T2DM related fatalities each year $(1,2)$. T2DM poses a major global health challenge for the modern health system as one-tenth of every dollar spent on global healthcare is on treating T2DM related complications (1). The devastating effect of T2DM on global health highlights the need to understand its risk factors in order to design better prevention plans and treatment strategies.

Existing evidence from genetic epidemiological studies and randomized control trials designed to intervene with $\mathrm{T} 2 \mathrm{DM}$ risks suggest its multifactorial origin with significant contribution from genetic, environmental, and behavioral factors $(3,4)$. Although, many of these causal factors are individual-specific (e.g., smoking, exercise) $(5,6,7,8)$, several others are population-specific (e.g., nature and content of diets, genetic component) $(4,9)$ as well as environment-specific (e.g., gut microbiome, sedentary lifestyle) $(10,11)$ that significantly differ across different ethnic populations. These behavioral and environmental factors contribute to diabetes by controlling the gene expression through epigenetic mechanisms (e.g., DNA methylation, histone modification, chromatin remodeling) (12,13). For instance, exercise can cause hypermethylation of the DNA promoter in lipogenesis-associated HDAC4 and NCOR2 genes, leading to their decreased expression in humans (14). Further, DNA methylation affects expression of genes related to T2DM pathophysiology in pancreatic $\beta$-cell (15), adipose tissue (16), and skeletal muscle $(17,18)$. Thus, identification of mechanisms showing how DNA methylation variations present in individuals across different ethnicity confer risk to T2DM is important to better understand the disease biology (19).

Previous epigenome-wide association (EWA) and candidate-based studies have identified more than 60 differentially methylated $\mathrm{CpG}$ sites in more than 40 genes (e.g., TXNIP) as risk loci for T2DM (http://ewascatalog.org/?trait=type\%20ii\%20diabetes). However, these individual CpG sites have a small influence over T2DM risk as observed from their small effect size and minor methylation differences at the loci between patients and healthy controls. The small effect size of the $\mathrm{CpG}$ sites further indicates that a coordinated methylation or demethylation at multiple $\mathrm{CpG}$ sites in a specific region (e.g., promoter, gene body) of a gene or group of genes is required to bring the necessary changes in disease-related gene expression (20). Hence, it is crucial to study the group behavior (co-methylation) of identified $\mathrm{CpG}$ sites to decipher the coordination among respective genes affecting the disease process. However, despite the growing literature describing the role of DNA methylation in T2DM biology, the co-methylation behavior of the identified $\mathrm{CpG}$ sites, and their role in T2DM risk is largely unknown (19).

To fill the gap in knowledge, the current study firstly identifies differentially methylated CpG sites between healthy controls and T2DM patients in 844 subjects of Indo-European origin from Indian population. Our results replicated 3 earlier known signals in the Indian population and identified 6 novel differentially methylated $\mathrm{CpG}$ sites in the T2DM patients that also associate with other T2DM-risk factors (e.g., BMI, lipids). Secondly, our study utilized the Weighted gene expression 
network analysis (WGCNA) (21), a commonly used systematic algorithm, to identify the coexpressed group of genes which significantly affects the disease risk from a dataset consisting of thousands of genes. WGCNA has been used to identify genes, microRNAs (miRNAs), and long noncoding RNAs (lncRNAs) significantly correlated with progression, prognosis, metastasis, and recurrence in multiple diseases $(22,23,24)$. With the help of WGCNA, we identified 4 comethylated modules among the differentially methylated $\mathrm{CpG}$ sites. We further explored the mechanism for regulation of methylation in $\mathrm{CpG}$ sites of identified modules using methylationquantitative trait loci (methQTL) analysis. Consequently, we identified a novel co-methylated module consisting of 28 differentially methylated $\mathrm{CpG}$ sites with the $J U P$ gene as the central node. All the hub genes in the module were regulated by a methQTL (rs6503650) in the JUP gene.

\section{Methods}

\section{Study population and measurements of clinical parameters}

The ethnicity of every study participant (Indian) is of Indo-European origin and they are member of the INdian DIabetes COnsortium (INDICO) $(25,26)$. T2DM patients have been recruited from Diabetes Clinics from the Department of Endocrinology, Metabolism \& Diabetes, All India Institute of Medical Sciences (AIIMS). We defined T2DM according to the World Health Organization criteria, as a condition with any of the following characteristics: (i) fasting glucose level of $\geq 126 \mathrm{mg} / \mathrm{dl}$ ( $7.0 \mathrm{mmol} / \mathrm{L}$ ), (ii) 2-hour postprandial glucose $\geq 200 \mathrm{mg} / \mathrm{dl}$, (iii) glycosylated HbA1C level $>6.5 \%$. Diseased subjects with an age of onset below 30 years were also excluded to avoid mix-up with type 1 diabetes.

The controls have been recruited by organizing health awareness camps in the community $(27,28)$ around Delhi and nearby areas and were defined as (i) $>40$ years of age; (ii) HbA1c level $<6.0 \%$; (iii) fasting plasma glucose level $<110 \mathrm{mg} / \mathrm{dL}(6.1 \mathrm{mmol} / \mathrm{L})$; (iv) no family history of diabetes in first-degree relatives; and (v) urban dwellers. Informed written consent was obtained from all the participants of the study. The ethnicity of the subject was defined primarily based on the geographical location of the recruitment along with their birthplace and place of origin of both the parents. Pregnant women and individuals of other ethnicities were excluded from the study. The characteristics of the study participants have been shown in Supplementary Table 1. All study participants have been well characterized for their anthropometrical (e.g., height, weight, waist circumference, and hip circumference), and biochemical measures (e.g., fasting glucose, glycosylated hemoglobin (HbA1C), insulin, C-peptide, total cholesterol, HDL, LDL, triglycerides, C-reactive protein (CRP), as mentioned previously $(26,29,30)$. Questionnaires assessing cigarette smoking status (coded as current smoker/ex-smoker/never), alcohol consumption status (coded as regular/sporadic/never), and level of leisure-time physical activities (coded as regular/sporadic/never) were recorded. The study was approved by the ethics committees of the participating institutes and carried out in accordance with the principles of the Helsinki Declaration. 


\section{Discovery phase DNA methylation assay and quality control analysis}

We performed the Infinium assay using HumanMethylation450 BeadChip for 524 (260 T2DM+264 controls) Indian individuals of Indo-European origin. The genomic DNA required for the assay was extracted from peripheral blood leukocytes using the salting-out process as mentioned previously (31). Bisulfite conversion of $700 \mathrm{ng}$ genomic DNA was performed using EZ-96 DNA Methylation Kit (Deep Well Format) (Zymo Research; Irvine, CA, USA) in accordance with the given kit instructions (www.zymoresearch.com). The Infinium assay for genome-wide DNA methylation using HumanMethylation450 BeadChip was performed as per the manufacturer's instruction. Briefly, bisulfite-converted DNA was sequentially alkali denatured, neutralized, isothermally amplified by incubating at $37^{\circ} \mathrm{C}$ for 22 hours, end-point enzymatically fragmented, purified, and hybridized on an Infinium ${ }^{\circledR}$ HumanMethlyation450 BeadChip at $48^{\circ} \mathrm{C}$ for 18 hours, as described previously $(31,32)$. The BeadChip was washed to remove any free or non-specifically hybridized DNA; the hybridized probes were single-base extended and was stained with multiple layers of fluorescence. Finally, BeadChip was coated and scanned using Illumina ${ }^{\circledR}$ iScan system. The image files were analyzed using the minfi package in R (Supplementary Figure 1) (33). The analysis involves background subtraction, fixing the outlier methylation values using "fixMethOutliers" option in the minfi package. We removed samples which could not pass the quality control (QC) measures. We excluded 2 samples with a call rate $<95 \%$ for probes, 4 poor-quality samples having at least $1 \%$ of CpG sites with detection $p$-value less than $0.01,1$ sample with bisulfite failure (intensity lesser than $3 \mathrm{SD}$ of the mean value for $\mathrm{C} 1$, $\mathrm{C} 2, \mathrm{C} 3$, and $\mathrm{C} 4$ probes present in the chip) and 1 sample with possible gender mismatch based on evaluation of selected $\mathrm{CpG}$ sites on the Y chromosome, leaving a total of 504 samples available for further analysis (Supplementary Figure 1). At the $\mathrm{CpG}$ sites level, we removed $457 \mathrm{CpG}$ sites that had a bead count $<3$ in $5 \%$ of samples, $831 \mathrm{CpG}$ sites with average detection p-value of $>0.01$ in $1 \%$ of samples and $570 \mathrm{CpG}$ sites with call rate $<98 \%$. We also removed 30903 crosshybridization probes present in the supplementary file of Chen et al [34] and $15781 \mathrm{CpG}$ sites containing SNP on the probe. In addition, we removed $10277 \mathrm{CpG}$ sites present in sex chromosomes. The analysis plan details along with various quality control steps, number of samples and CpG sites removed, have been shown in Supplementary Figure 1.

The data was normalized using the beta-mixture quantile normalization (BMIQ) model to remove the technical variability inherent in two different types of probes present in HumanMethylation450 BeadChip (35). We estimated different WBC cell compositions using the Housman Algorithm based on methylation level of $500 \mathrm{CpG}$ and used linear regression to regress out the effect of age, sex, smoking status, alcohol consumption, diet, bisulfite conversion efficiency, and cell compositions over methylation level of each probe (36). Wilcoxon test was used to compare the mean methylation difference between T2DM subjects and healthy controls for $426693 \mathrm{CpG}$ sites in 504 subjects (254 T2DM subjects and 250 controls) using IMA packages in R. A p-value of $<$ $1.2 \times 10^{-7}(0.05 / 426693)$ was considered significant after Bonferroni correction for the number of CpGs. The inflation factor for the association was 1.67 that is apparently high but genomic inflation is often discussed as endemic to epigenome-wide association studies (EWAS) $(37,38)$. 


\section{Selection of CpG sites for replication}

We validated the top identified signals using the EpiTYPER (39) assay in 320 individuals (157 $\mathrm{T} 2 \mathrm{DM}+163$ control). We selected a total of $17 \mathrm{CpG}$ sites for validation, which included the top 4 differentially methylated $\mathrm{CpG}$ sites based on $\mathrm{p}$-value and 1 site with maximum $\beta$-differences between case and control groups as significant $\mathrm{CpG}$ sites with an assumption that a larger difference could also influence the disease (Supplementary Table 2, Supplementary Figure 2).

We also used data-driven approaches for $\mathrm{CpG}$ selection for the validation phase. To identify T2DM associated $\mathrm{CpG}$ sites with the effect on other T2DM related traits, the association of $535 \mathrm{CpG}$ sites was sought in controls, with extreme distribution for T2DM related traits such as glycaemic parameters, obesity-related parameters, lipid-related parameters, and insulin-related parameters. We compared the methylation level of the 535 identified CpG sites in subjects with a measurement below $10^{\text {th }}$ percentile and above $90^{\text {th }}$ percentile for extreme level for T2DM risk related phenotypes. This approach was supplemented with the role of corresponding genes in relation to respective phenotypes in literature. Based on this approach, we selected 17 signals for the validation phase using EpiTYPER assay (39).

Validation of significant signals from discovery phase in an independent set of samples using the EpiTYPER assay

For EpiTYPER assay, bisulfite-converted primers corresponding to 600 base pair passing the selected CpG sites were designed using EpiDesigner software (http:/www.epidesigner.com/) (39). Bisulfite converted DNA (700ng) was performed using Zymo EZ-96 methylation kit by following the manufacture's protocol. PCR reactions were performed in duplicates using bisulfite DNA and Agena PCR chemicals, followed by in-vitro transcription and uracil-based cleavage using RNAse A. The cleaved products were assessed using "time of flight" mass spectroscopy and methylation levels were quantified. The data was extracted and subjected for various QC steps using "MAssArray" package in R. We removed CpG sites if they have called $<80 \%$ of subjects among total subjects. $\mathrm{CpG}$ sites having overlapping masses with other $\mathrm{CpG}$ sites were also excluded. Samples showing $>20 \%$ of $\mathrm{CpG}$ sites as missing, were also discarded. Next, an average methylation value from PCR duplicates was estimated and used for further downstream analysis. We considered a p-value less than $2.94 \times 10^{-3}(0.05 / 17)$ for replication of signals in the $2^{\text {nd }}$ phase considering multiple comparisons for 17 tests.

\section{Meta-analysis of the summary statistics from the discovery and validation phase}

We meta-analysed the replicated signals using the metacont function in "meta" packages in R (40).

Construction of weighted gene co-methylation network of top signals: Since network-based analysis allows assessing combined effect of differentially methylated $\mathrm{CpG}$ sites over disease risk, we constructed a weighted undirected co-methylation network in 264 controls using the methylation data for $535 \mathrm{CpG}$ sites differentially methylated $\left(\mathrm{p}<1.2 \times 10^{-7}\right)$ between T2DM and 
healthy subjects using the WGCNA package in R (21). Within the network, nodes represented significant $\mathrm{CpG}$ sites and edges between nodes represented correlation between the $\mathrm{CpG}$ sites. We used a soft threshold power of 6 , minimum module detection size of 10 , fixed height cut-off to 0.25 , and biweight mid-correlation as a measure of similarity and all other default settings for network construction. We defined modules in the network using the dynamic tree-cutting algorithm on the dendrogram, obtained from the hierarchical clustering option as provided in WGCNA. Furthermore, the connection strength between two nodes (CpG sites) of the module was estimated as the overlap in connection pattern between two nodes. Briefly, less connection strength denotes a poor correlation between module members. The gene connectivity is calculated by taking the sum of connection strengths with other genes. Module members with connectivity $>0.80$ were defined as hub $\mathrm{CpG}$ sites. Module members with connectivity $<0.1$ were removed from the modules to visualize the module structure clearly.

Lastly, we validated the preservation of modules in 254 T2DM subjects (Figure 2b) and another independent dataset of 55 individuals (28 individuals of Northern European ethnicity living in the USA for several generations and 27 migrant Indians to the USA who migrated for at least five years) (data not shown) (41) using the "modulePreservation" command in WGCNA (21). WGCNA calculates Z-summary, which is the measure of preservation of average of density measures (Zdensity) and connectivity measures (Zconnectivity) between the test and reference network. The higher the Z-summary score the higher the preservation and median preservation rank. Visualization of module structure and topology of the brown module was done using Cytoscape (42).

\section{Construction of module-trait relationships and identification of hub CpG sites associated with clinical modules:}

Pearson's correlation coefficients and P-values between modules eigenvalues and T2DM-related traits were calculated using WGCNA packages and visualized in a module-trait table. The higher the Pearson Co-relation Coefficients between eigengenes and the clinical variable will reflect the stronger role of module methylation in relation to phenotype. A module that affects a larger number of risk factors could be interesting for further mining and functional studies. A correlation coefficient with a p-value $<0.05$ was considered significant.

Functional enrichment analysis of the CpGs associated genes from the key modules: We performed pathway analysis and gene enrichment analysis for identified modules using GENECODIS to get an insight about the possible mode of action of identified modules in the biology of T2DM (43).

\section{Power analysis}

We calculated $100 \%$ power of the study using "pwr" packages in R. Power analysis was performed for 500 samples using a significance level of $1 \times 10^{-7}$, average $\beta$-difference of 0.01 and, the average standard deviation for probes was 0.026 . 


\section{Results \\ Epigenome-wide association study for T2DM in Indians identified 6 novel loci in Indian populations}

The result showed differential methylation for $535 \mathrm{CpG}$ sites at a $\mathrm{p}$-value of $1.2 \times 10^{-}$ ${ }^{07}(0.05 / 426693)$. The list of differentially methylated $\mathrm{CpG}$ sites has been shown in Additional file 1. Distributions of p-values across different chromosomes have been shown in the Manhattan plot (Figure 1). We detected a CpG $\operatorname{cg} 19693031$ in TXNIP as the top signal in the Indian population. Replication of 17 selected CpG sites using EpiTYPER assay was performed in 320 independent samples (157 T2DM+163 controls) and data was analyzed using the "MassArray" package in R. We observed a strong correlation (Pearson correlation of 0.76 at a p-value of $2.69 \times 10^{-5}$ for cg01178710 in MIR1287 gene, median correlation of 0.63 ) between Illumina 450K technology and EpiTYPER assay measurements (Supplementary Figure 3).

Meta-analysis of summary statistics from both the phases revealed differential methylation of 9 CpG sites between healthy and T2DM patients at the epigenome wide significance level in Indian population ( $\mathrm{p}$-value of $<1 \times 10^{-7}$, Table 1) (44). We also replicated signals cg19693031 in TXNIP ( $\beta$ $=-0.05, \mathrm{p}$-value $\left.=2.16 \times 10^{-16}\right)$ and $\operatorname{cg} 11024682$ in $\operatorname{SREBF1}\left(\beta=0.02, \mathrm{p}\right.$-value $\left.=3.02 \times 10^{-10}\right)$ and $\operatorname{cg} 00574958$ in $C P T 1 A\left(\beta=-0.01, \mathrm{p}\right.$-value $\left.=1.43 \times 10^{-8}\right)$ in Indian population living in India (Table 1). We identified 6 novel signals viz cg16171771 in PDCD61P, cg01178710 in MIR1287, cg04673737 in 5s_rRNA, cg24458314 in HDAC9, cg23372795 in KCNK16, and cg15815318 in RTN1 as differentially methylated in case of T2DM in Indian population (Table 1).

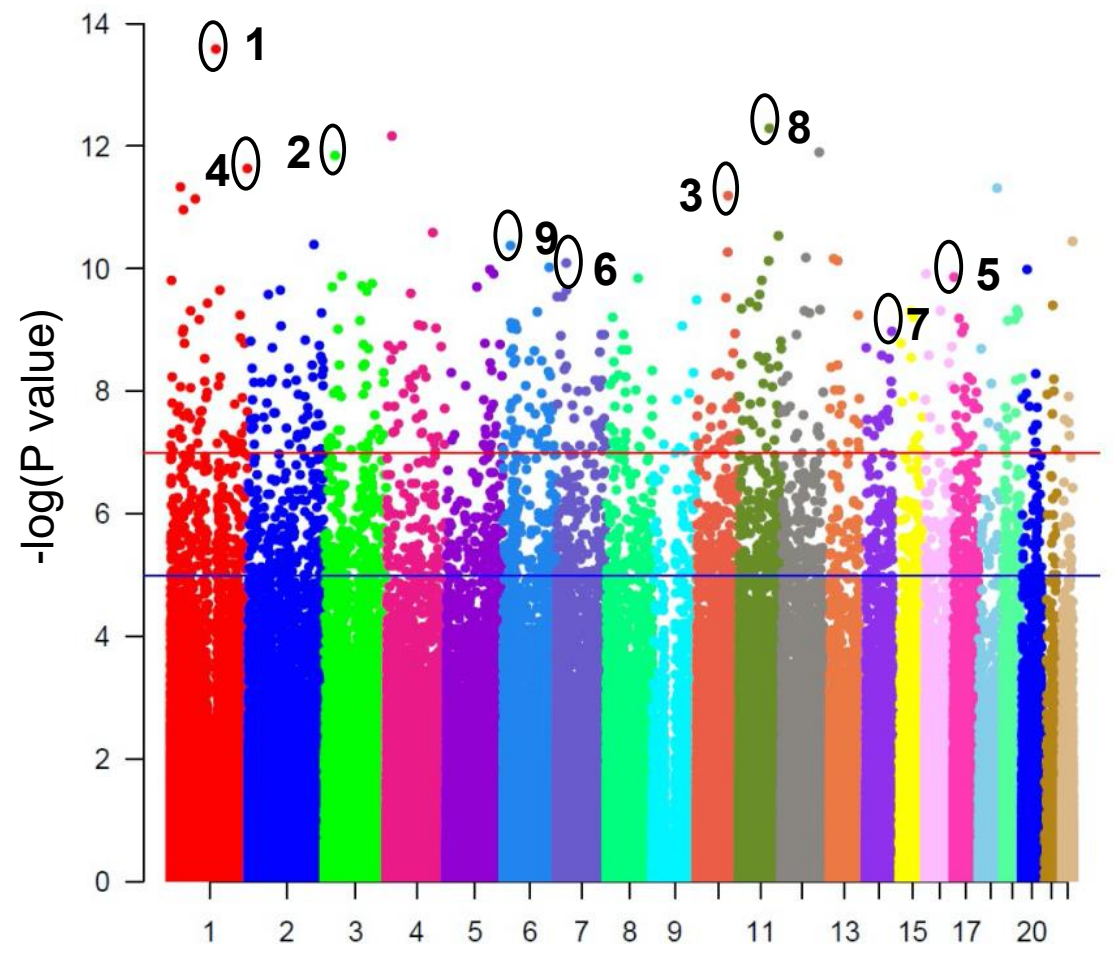

1. cg19693031-TXNIP

2. $\operatorname{cg} 16171771-P D C D 6 I P$

3. $\operatorname{cg} 01178710-M I R 1287$

4. cg04673737-5s_RNA

5. $c g 11024682-S R E B F 1$

6. cg24458314-HDAC9

7. cg15815318-RTN1

8. cg00574958-CPT1A

9. cg23372795-KCNK16

Chromosomes 
Figure 1: Manhattan plot showing the distribution of p-values for analyzed markers across different chromosomes. Manhattan plot for CpG sites differentially methylated between T2DM and healthy control in the discovery phase. The -log10 p-values for the association of CpG sites are plotted as a function of genomic position (National Center for Biotechnology Information Build 38). The p-values were determined using Wilcox Test in the discovery phase of analysis. Each chromosome (Chr) has been represented with a unique color.

Table 1: CpG sites showing differential methylation at epigenome-wide significance levels in the meta-analysis

\begin{tabular}{|c|c|c|c|c|c|c|c|c|c|c|c|c|}
\hline \multicolumn{4}{|c|}{ CpG information } & \multicolumn{3}{|c|}{ Discovery phase } & \multicolumn{3}{|c|}{ Replication phase } & \multicolumn{3}{|c|}{ Combined analysis } \\
\hline CHR & CpG & Gene & $\begin{array}{l}\text { Nearest } \\
\text { gene }\end{array}$ & $\begin{array}{l}\text { T2DM/ } \\
\text { Control }\end{array}$ & $\begin{array}{c}\Delta \text { beta }\left(\mu_{\text {case }}-\right. \\
\left.\mu_{\text {control }}\right)\end{array}$ & P-value & $\begin{array}{l}\text { T2DM/ } \\
\text { Control }\end{array}$ & $\Delta$ beta $\left(\mu_{\text {case }}-\mu_{\text {control }}\right)$ & P-value & $\Delta$ beta & P-value & Dir \\
\hline 1 & $\operatorname{cg} 19693031$ & $T X N I P$ & 3'UTR & $252 / 252$ & $-0.05(-0.02-0.02)$ & $2.67 \times 10^{-14}$ & & $-0.04(-0.03-0.02)$ & $5.00 \times 10^{-3}$ & -0.05 & $2.16 \times 10^{-16}$ & -- \\
\hline 3 & $\operatorname{cg} 16171771$ & PDCD6IP & Intergenic & $252 / 252$ & $-0.02(-0.01-0.01)$ & $1.44 \times 10^{-12}$ & $152 / 164$ & $0.00(0.00--0.00)$ & 0.46 & -0.02 & $1.03 \times 10^{-11}$ & -+ \\
\hline 10 & $\operatorname{cg} 01178710$ & MIR1287 & Intergenic & $252 / 252$ & $-0.02(-0.01-0.01)$ & $6.36 \times 10^{-12}$ & $157 / 163$ & $0.04(0.03-0.02)$ & $1.82 \times 10^{-8}$ & -0.02 & $6.77 \times 10^{-10}$ & -- \\
\hline 1 & cg04673737 & $5 S \_r R N A$ & Intergenic & $252 / 252$ & $-0.02(-0.01-0.01)$ & $1.12 \times 10^{-11}$ & $85 / 89$ & $-0.03(-0.02--0.02)$ & 0.03 & -0.02 & $1.47 \times 10^{-9}$ & -- \\
\hline 17 & $\operatorname{cg} 11024682$ & SREBF1 & Body & $252 / 252$ & $0.02(0.01--0.01)$ & $6.63 \times 10^{-10}$ & $135 / 132$ & $0.00(0.00-0.00)$ & 0.05 & 0.02 & $3.02 \times 10^{-9}$ & ++ \\
\hline 7 & $\operatorname{cg} 24458314$ & HDAC9 & Body & $252 / 252$ & $-0.02(-0.01-0.01)$ & $2.92 \times 10^{-10}$ & $138 / 131$ & $-0.10(0.03-0.07)$ & $1.48 \times 10^{-5}$ & -0.02 & $3.50 \times 10^{-9}$ & -- \\
\hline 14 & $\operatorname{cg} 15815318$ & RTN1 & Body & $252 / 252$ & $-0.02(-0.01-0.01)$ & $3.44 \times 10^{-8}$ & $130 / 131$ & $-0.01(0.00-0.00)$ & 0.14 & -0.02 & $7.64 \times 10^{-9}$ & -- \\
\hline 11 & $\operatorname{cg} 00574958$ & CPT1A & 5'UTR & $252 / 252$ & $-0.01(-0.01-0.01)$ & $1.50 \times 10^{-8}$ & $157 / 163$ & $-0.02(-0.01-0.01)$ & $7.01 \times 10^{-4}$ & -0.01 & $1.43 \times 10^{-8}$ & -- \\
\hline 6 & $\operatorname{cg} 23372795$ & KCNK16 & Body & $252 / 252$ & $-0.02(-0.01-0.01)$ & $3.11 \times 10^{-9}$ & $157 / 163$ & $-0.012(0.01--0.01)$ & 0.89 & -0.02 & $1.66 \times 10^{-8}$ & -- \\
\hline
\end{tabular}

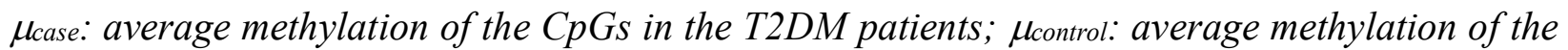
CpGs in the healthy control; $\Delta$ beta: difference between average methylation in T2DM patients and healthy control; UTR: Untranslated region. Signals that were differentially methylated at a $p$-value $<5 \times 10^{-8}$ in the meta-analysis have been reported in the letter.

\section{Identified CpG sites associates with T2DM risk factors}

To understand the possible action mechanism in the observed differential methylation over T2DM risk, we performed an association analysis of the identified signals with other T2DM risk factors (e.g., BMI, lipids, etc) in cases and control subject separately. The hypothesis being that DNA methylations at these significant loci alter the level of T2DM risk factors. The analysis revealed a significant association of identified $\mathrm{CpG}$ sites with fasting glucose, triglycerides, LDL, CRP, uric acid, creatinine, insulin, and obesity measures (e.g., BMI). For example, cg19693031 in TXNIP associated with fasting glucose, HbA1c, cholesterol, triglycerides, and LDL level in T2DM cases and WHR measurements in control subjects (Table 2). We observed an association of cg19693031 in TXNIP with hyperglycemia in Indian population similar to the Caucasian population from Spain (45). The association of identified signals with T2DM risk factors suggest a shared epigenetic contributor amongst them. 
Table 2: Table showing association of methylation of identified CpG sites with other T2DM risk factors in healthy individuals

\begin{tabular}{|c|c|c|c|c|c|}
\hline & & \multicolumn{2}{|c|}{ Controls } & \multicolumn{2}{|l|}{ T2DM } \\
\hline CpG sites & Trait & Effect(SE) & $\mathrm{P}$ & Effect(SE) & $\mathrm{P}$ \\
\hline cg19693031 (TXNIP) & Fasting glucose & $-27.80(14.82)$ & 0.06 & $-220.5(59.26)$ & $2.49 \times 10^{-4}$ \\
\hline cg19693031 (TXNIP) & HbA1c & $-0.96(0.59)$ & 0.11 & $-12.52(2.01)$ & $1.92 \times 10^{-09}$ \\
\hline cg19693031 (TXNIP) & Cholesterol & $-81.28(51.42)$ & 0.12 & $-244.67(44.37)$ & $8.88 \times 10^{-08}$ \\
\hline cg19693031 (TXNIP) & Triglycerides & $-168.04(93.46)$ & 0.07 & $-650.79(124.52)$ & $3.66 \times 10^{-07}$ \\
\hline cg19693031 (TXNIP) & LDL & $-39.90(44.08)$ & 0.37 & $-171.67(34.99)$ & $1.74 \times 10^{-07}$ \\
\hline cg19693031 (TXNIP) & WHR & $-0.24(0.12)$ & 0.04 & $0.007(0.05)$ & 0.89 \\
\hline cg16171771 (PDCD6IP) & Triglycerides & $-5.15(113.35)$ & 0.96 & $-486.83(215.12)$ & 0.02 \\
\hline cg16171771 (PDCD6IP) & LDL & $-106.77(52.78)$ & 0.04 & $-42.36(64)$ & 0.5 \\
\hline cg16171771 (PDCD6IP) & C-reactive protein & $7.02(4.63)$ & 0.13 & $23.46(11.42)$ & 0.04 \\
\hline cg16171771 (PDCD6IP) & WHR & $-0.3(0.14)$ & 0.03 & $-0.01(0.09)$ & 0.85 \\
\hline cg01178710(MIR1287) & C-reactive protein & $11.04(4.66)$ & 0.02 & $29.3(11.95)$ & 0.02 \\
\hline $\operatorname{cg} 01178710(\mathrm{MIR} 1287)$ & Creatinine & $-0.11(0.29)$ & 0.7 & $3.64(1.52)$ & 0.02 \\
\hline $\operatorname{cg} 01178710(\mathrm{MIR} 1287)$ & Uric acid & $-0.93(2.43)$ & 0.7 & $6.06(2.78)$ & 0.03 \\
\hline cg04673737(5s_rRNA) & C-reactive protein & $10.18(3.39)$ & $\begin{array}{c}2.9 \times 10^{-} \\
3\end{array}$ & $26.76(8.78)$ & 0.003 \\
\hline cg04673737(5s_rRNA) & Creatinine & $-0.41(0.21)$ & 0.05 & $2.84(1.12)$ & 0.01 \\
\hline cg04673737(5s_rRNA) & WHR & $-0.10(0.11)$ & 0.32 & $0.17(0.07)$ & 0.02 \\
\hline cg04673737(5s_rRNA) & BMI & $12.7(4.94)$ & 0.01 & $1.34(5.44)$ & 0.8 \\
\hline cg24458314 (HDAC9) & C-reactive protein & $8.55(4.05)$ & 0.04 & $23.46(10.39)$ & 0.03 \\
\hline $\operatorname{cg} 11024682($ SREBF1) & Fasting glucose & $-34.62(17.85)$ & 0.05 & $167.85(103.48)$ & 0.11 \\
\hline $\operatorname{cg} 11024682($ SREBF1) & Insulin & $23.11(11.65)$ & 0.05 & $-46.59(53.47)$ & 0.38 \\
\hline $\operatorname{cg} 11024682($ SREBF1) & $\mathrm{HbA} 1 \mathrm{c}$ & $-0.19(0.72)$ & 0.79 & $7.42(3.59)$ & 0.04 \\
\hline $\operatorname{cg} 11024682($ SREBF1) & Triglycerides & $271.72(112)$ & 0.02 & $571.88(219.02)$ & 0.01 \\
\hline cg11024682(SREBF1) & BMI & $15.74(6.65)$ & 0.02 & $8.10(7.15)$ & 0.25 \\
\hline cg11024682(SREBF1) & Creatinine & $0.58(0.29)$ & 0.04 & $1.99(1.50)$ & 0.19 \\
\hline cg23372795(KCNK16) & LDL & $-89.92(38.21)$ & 0.02 & $10.49(44.07)$ & 0.81 \\
\hline $\operatorname{cg} 23372795(\mathrm{KCNK} 16)$ & Cholesterol & $-98.93(44.77)$ & 0.02 & $-32.01(55.24)$ & 0.56 \\
\hline cg23372795(KCNK16) & C-reactive protein & $9.56(3.31)$ & 0.004 & $26.35(7.93)$ & $1.03 \times 10^{-3}$ \\
\hline cg23372795(KCNK16) & Creatinine & $-0.24(0.21)$ & 0.24 & $2.64(1.02)$ & 0.01 \\
\hline cg23372795(KCNK16) & Waist-hip ratio & $-0.21(0.1)$ & 0.04 & $0.13(0.06)$ & 0.05 \\
\hline $\operatorname{cg} 00574958(\mathrm{CPT} 1 \mathrm{~A})$ & Insulin & $-31.25(15.25)$ & 0.04 & $-102.46(72.94)$ & 0.16 \\
\hline
\end{tabular}




\begin{tabular}{|c|c|c|c|c|c|}
$\operatorname{cg} 00574958(\mathrm{CPT} 1 \mathrm{~A})$ & Triglycerides & $-426.52(145.67)$ & $\begin{array}{c}3.7 \times 10^{-} \\
3\end{array}$ & $-862.57(298.33)$ & $4 \times 10^{-3}$ \\
\hline $\operatorname{cg} 00574958(\mathrm{CPT} 1 \mathrm{~A})$ & C-reactive protein & $-22.03(5.96)$ & $3 \times 10^{-4}$ & $-33.10(15.94)$ & 0.04 \\
\hline $\operatorname{cg} 00574958(\mathrm{CPT} 1 \mathrm{~A})$ & WHR & $-0.46(0.19)$ & 0.01 & $-0.06(0.12)$ & 0.63 \\
\hline $\operatorname{cg} 00574958(\mathrm{CPT} 1 \mathrm{~A})$ & Uric acid & $-9.73(3.08)$ & $\begin{array}{c}1.8 \times 10^{-} \\
3\end{array}$ & $-8.78(3.69)$ & 0.02 \\
\hline $\operatorname{cg} 15815318(\mathrm{RTN} 1)$ & C-reactive protein & $11.95(3.53)$ & $8 \times 10^{-4}$ & $22.43(9.29)$ & 0.02 \\
\hline $\operatorname{cg} 15815318(\mathrm{RTN} 1)$ & WHR & $-0.13(0.11)$ & 0.21 & $0.17(0.07)$ & 0.02 \\
\hline $\operatorname{cg} 15815318(\mathrm{RTN} 1)$ & BMI & $10.23(5.16)$ & 0.04 & $-7.19(5.62)$ & 0.2 \\
\hline
\end{tabular}

The effect size and p-value are shown in the table obtained after linear regression considering the risk factors as the dependent variable and DNA methylation of the CpG sites as the independent variable in the discovery phase sample of the study. A p-value of 0.05 has been considered significant. SE: Standard error, BMI: Body Mass Index; WHR: Waist hip ratio; LDL: Low-density lipids.

\section{Identified signals are co-methylated in T2DM patients and associated with its risk factors}

Since methylation at a single $\mathrm{CpG}$ site usually has a smaller effect on the disease risk, many $\mathrm{CpG}$ sites in the same gene or in a group of genes may work in tandem in a coordinated fashion to confer risk to the disease. To identify such co-methylated $\mathrm{CpG}$ sites, we constructed a methylationbased network of 535 differentially methylated $\mathrm{CpG}$ sites in 163 controls from the discovery phase of the study using WGCNA package in R. Our analysis identified 4 distinct modules, namely turquoise (296 CpG sites), blue (123 CpG sites), brown (28 CpG sites), and yellow (21 CpG sites), as shown in Figure 2a. We validated the preservation of modules in 254 independent T2DM subjects (Figure 2b) and in another data set of 55 independent individuals (28 individuals of Northern European ethnicity living in the USA for several generations and 27 migrant Indians to the USA who have migrated for at least five years) (data not shown). All 4 modules showed moderate to strong preservation of co-methylation pattern in both the validation datasets (Zsummary $>2$, Figure $2 \mathrm{~b}$ ) suggesting that co-methylation patterns between these CpG sites are reproducible across independent sample sets. Enrichment analysis for nearby genes of module's CpG sites revealed significant enrichment of purine metabolism pathway genes (e.g., ENTPD4, $A D K, P O L R 3 D$, and POLE genes) in the blue module and 8 other pathways (e.g., wnt signalling pathways, calcium signalling pathways) in the turquoise module (Supplementary Table 3). 

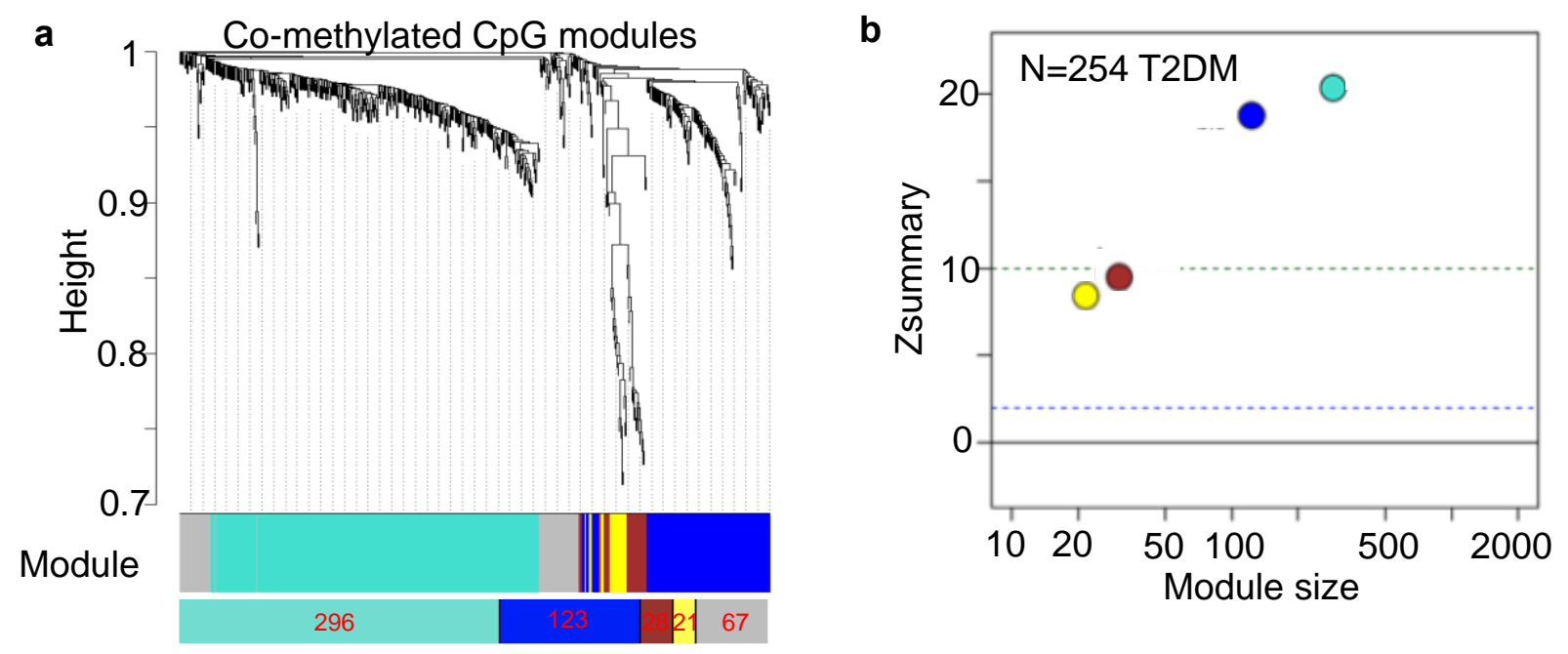

\begin{tabular}{|c|c|c|c|c|c|c|c|c|c|}
\hline Modules & BMI & Cholestrol & HDL & LDL & $\begin{array}{c}\text { C- } \\
\text { peptide }\end{array}$ & Insulin & HbA1c & BP (Sys) & $\begin{array}{c}\text { BP } \\
\text { (Dia) }\end{array}$ \\
\hline & $\begin{array}{c}0 \\
(1)\end{array}$ & \begin{tabular}{|c|c}
0 \\
$(1)$ \\
\end{tabular} & $\begin{array}{c}0.1 \\
(0.09)\end{array}$ & $\begin{array}{l}-0.05 \\
(0.4)\end{array}$ & $\begin{array}{c}0 \\
(0.9)\end{array}$ & $\begin{array}{c}-0.2 \\
(0.004)\end{array}$ & $\begin{array}{l}0.02 \\
(0.7)\end{array}$ & $\begin{array}{c}-0.2 \\
\left(2 \times 10^{-4}\right)\end{array}$ & $\begin{array}{c}-0.1 \\
(0.02)\end{array}$ \\
\hline & $\begin{array}{l}-0.05 \\
(0.4)\end{array}$ & $\begin{array}{r}-0.06 \\
(0.3)\end{array}$ & $\begin{array}{r}-0.07 \\
(0.2)\end{array}$ & $\begin{array}{l}-0.04 \\
(0.4)\end{array}$ & $\begin{array}{l}0.03 \\
(0.5)\end{array}$ & $\begin{array}{c}0.1 \\
(0.04)\end{array}$ & $\begin{array}{l}-0.07 \\
(0.2)\end{array}$ & $\begin{array}{c}0 \\
(0.8)\end{array}$ & $\begin{array}{c}0 \\
(0.8)\end{array}$ \\
\hline & $\begin{array}{c}0.1 \\
(0.03)\end{array}$ & $\begin{array}{l}0.07 \\
(0.2)\end{array}$ & $\begin{array}{r}-0.04 \\
(0.5)\end{array}$ & $\begin{array}{c}0.1 \\
(0.06)\end{array}$ & $\begin{array}{c}0.1 \\
(0.01)\end{array}$ & $\begin{array}{c}0.2 \\
(0.002)\end{array}$ & $\begin{array}{l}0.04 \\
(0.5)\end{array}$ & $\begin{array}{c}0.1 \\
(0.02)\end{array}$ & $\begin{array}{c}0.1 \\
(0.02)\end{array}$ \\
\hline & $\begin{array}{l}0.07 \\
(0.2)\end{array}$ & $\begin{array}{c}0.1 \\
(0.01)\end{array}$ & $\begin{array}{c}0.1 \\
(0.04)\end{array}$ & $\begin{array}{c}0.1 \\
(0.02)\end{array}$ & $\begin{array}{c}0.1 \\
(0.05)\end{array}$ & $\begin{array}{l}0.03 \\
(0.6)\end{array}$ & $\begin{array}{c}0.1 \\
(0.02)\end{array}$ & $\begin{array}{c}0 \\
(0.9)\end{array}$ & $\begin{array}{l}0.06 \\
(0.1)\end{array}$ \\
\hline
\end{tabular}

Figure 2: (a) Co-methylated modules among significant $C p G$ sites in the discovery phase of EWAS. WGCNA identified 4 modules (represented by 4 colors- turquoise, blue, brown, yellow) CpG sites not assigned to any module have been shown in grey. (b) Preservation of identified modules in 254 T2DM cases has been shown in a scatter plot between Zsummary and module's size. It indicates that the turquoise module has the highest level of Zsummary followed by blue, brown, and yellow modules, respectively. (c) Module-trait relationships. The rows represent the co-methylation module eigengene (ME) and its color. The columns represent clinically relevant traits in healthy individuals. The correlation has been shown as the upper number and P values have been shown as a lower number within each cell. The significant correlations have been marked in bold letters.

\section{MethQTL in JUP gene regulates hub genes of brown module}

We further explored the brown module in detail as its eigengene was associated with the maximum number of T2DM risk factors (BMI, C-peptide, insulin, and systolic as well as diastolic pressure, Figure 2c). Since the structural properties of a network module can reveal its possible function and identify the hub genes regulating the modules, we checked the structure of the brown module and explored the connection pattern between the member $\mathrm{CpG}$ genes. Connectivity analysis of the module revealed $14 \mathrm{CpG}$ sites as hub (connectivity $>0.8$ ) members (Supplementary Table 4). With the help of Cytoscape, we visualized the module which revealed 2 submodules connected by $\mathrm{CpG}$ 
in $J U P$ gene (Supplementary Figure 4). This suggests that methylation of $\mathrm{CpG}$ in $J U P$ may regulate other genes in the brown module and different submodules may be regulated by independent mechanisms.

To find the possible regulatory mechanism of hub genes of the brown module, we performed methQTL analysis for SNPs of JUP gene in Illumina $610 \mathrm{~K}$ quad BeadChip and methylation level of hub 14 hub CpG sites. Association analysis revealed that SNP rs6503650 in JUP gene significantly associates with methylation level of all $14 \mathrm{CpG}$ sites that have been identified as hub CpG sites for brown module including cg15223933 in JUP gene itself (Table 3). Results from methQTL analysis and structure of brown module correlated with each other, indicating that the $J U P$ gene and its variant rs6503650 plays important role in regulating module methylation behavior. Furthermore, it indicates that methylation of brown module genes is regulated by a common mechanism to mark their effect.

Table 3: Association of rs6503650 with methylation level of hub genes in brown module in methQTL analysis in 250 control subjects

\begin{tabular}{|c|c|c|c|c|c|c|}
\hline S. No. & $\mathrm{CpG}$ & Gene & SNP & Beta & SE & P-value \\
\hline 1 & $\operatorname{cg} 06055730$ & $F A M 54 A$ & \multirow{14}{*}{ rs6503650(C/A) } & 0.013 & 0.004 & $3.1 \times 10^{-04}$ \\
\hline 2 & $\operatorname{cg} 04583163$ & PIWIL3 & & 0.009 & 0.003 & $2.03 \times 10^{-03}$ \\
\hline 3 & $\operatorname{cg} 13675624$ & PLEKHG6 & & 0.01 & 0.003 & $2.40 \times 10^{-03}$ \\
\hline 4 & $\operatorname{cg} 17012502$ & $A C V R 1 C$ & & 0.008 & 0.003 & $3.23 \times 10^{-03}$ \\
\hline 5 & $\operatorname{cg} 15223933$ & $J U P$ & & 0.01 & 0.004 & $3.74 \times 10^{-03}$ \\
\hline 6 & $\operatorname{cg} 02854490$ & $N O B O X$ & & 0.01 & 0.003 & $4.11 \times 10^{-03}$ \\
\hline 7 & cg13936208 & RNF34 & & 0.008 & 0.003 & $5.50 \times 10^{-03}$ \\
\hline 8 & $\operatorname{cg} 08565320$ & TRNA Asp & & 0.009 & 0.003 & $5.85 \times 10^{-03}$ \\
\hline 9 & $\operatorname{cg} 07067773$ & $A B R A$ & & 0.01 & 0.004 & $6.08 \times 10^{-03}$ \\
\hline 10 & $\operatorname{cg} 18117601$ & ZSCAN18 & & 0.008 & 0.003 & 0.01 \\
\hline 11 & $\operatorname{cg} 09510269$ & $H C G 18$ & & 0.008 & 0.003 & 0.02 \\
\hline 12 & $\operatorname{cg} 10620911$ & AGPAT1 & & 0.009 & 0.004 & 0.02 \\
\hline 13 & $\operatorname{cg} 26020008$ & SPATA2 & & 0.008 & 0.003 & 0.02 \\
\hline 14 & $\operatorname{cg} 11021810$ & $F O X N 3$ & & 0.01 & 0.005 & 0.05 \\
\hline
\end{tabular}

The association status of rs6503650 (JUP) with methylation status of 14 hub CpGs in brown modules. A1/A2 = Allele1 and Allele2 for SNPs; Beta=Effect of in per A1 allele of SNP on methylation level of CpG sites. $P$-value $=P$-value of association for T2DM. The p-values, beta values, and standard errors have been obtained using linier regression considering the methylation at the CpGs as dependent variable and genotype at rs6503650 as independent variable.

\section{Hub genes of the brown module segregate T2DM patients with dyslipidemia with good}

\section{glycemic control}

We performed hierarchical clustering of the T2DM patients using the DNA methylation level of $14 \mathrm{CpG}$ sites. The combined power of these $\mathrm{CpG}$ sites stratified the T2DM cases into 3 groups 
with low, intermediate, and high levels of methylation $\mathrm{CpG}$ sites. Next, a comparison of the clinical parameters between these case groups showed significantly higher-level of triglycerides $(\mathrm{P}=0.01)$, lower level of $\operatorname{HDL}(\mathrm{P}=0.005)$, and $\mathrm{HbA1c}(\mathrm{P}=0.03)$ in patients with low methylation case group as compared to high methylation group was made This segregation of patients with distinct clinical phenotypes suggests that methylation at the hub $\mathrm{CpG}$ sites of the brown module can be used as useful markers to segregate patients with good glycemic control but with higher lipid level in clinics.
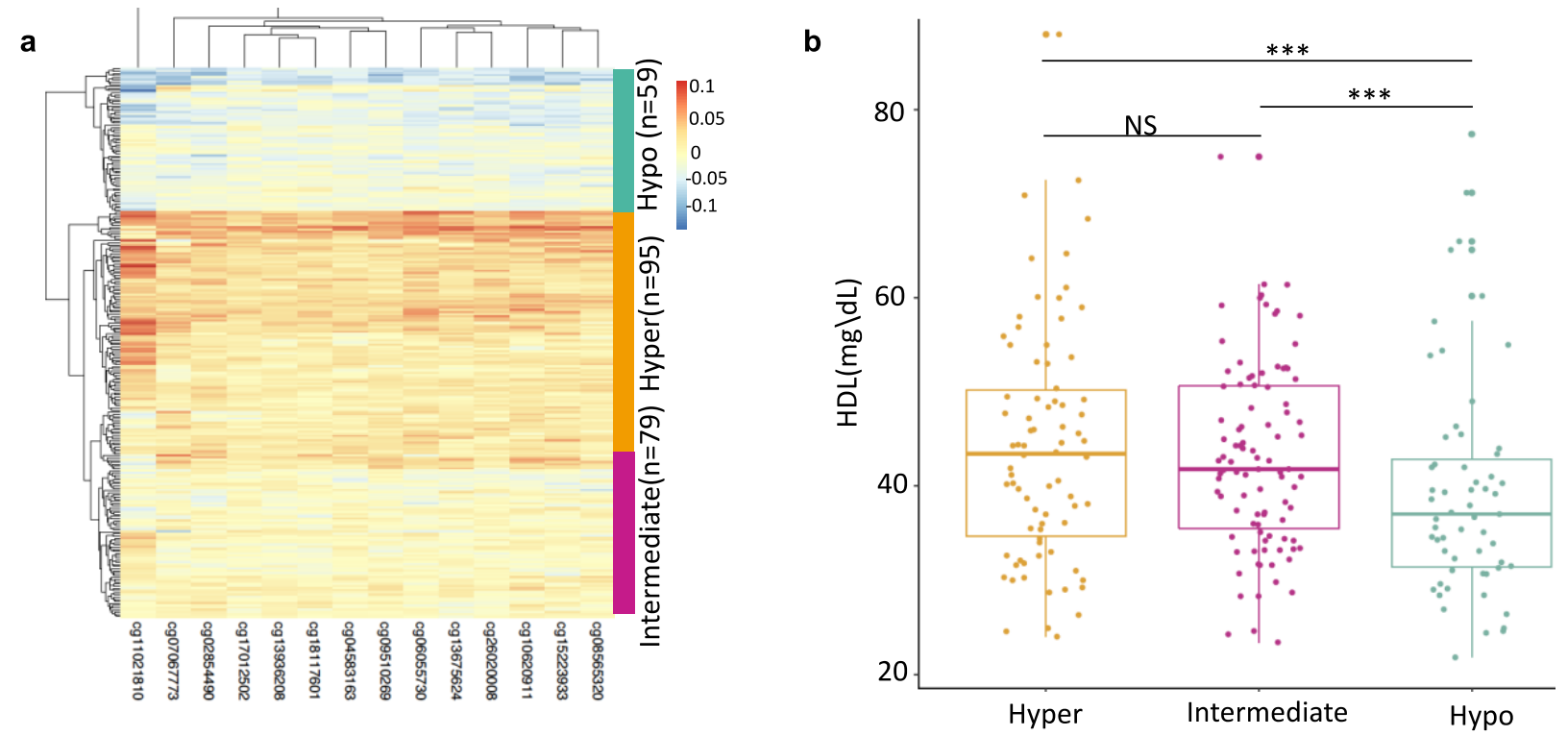

c

d
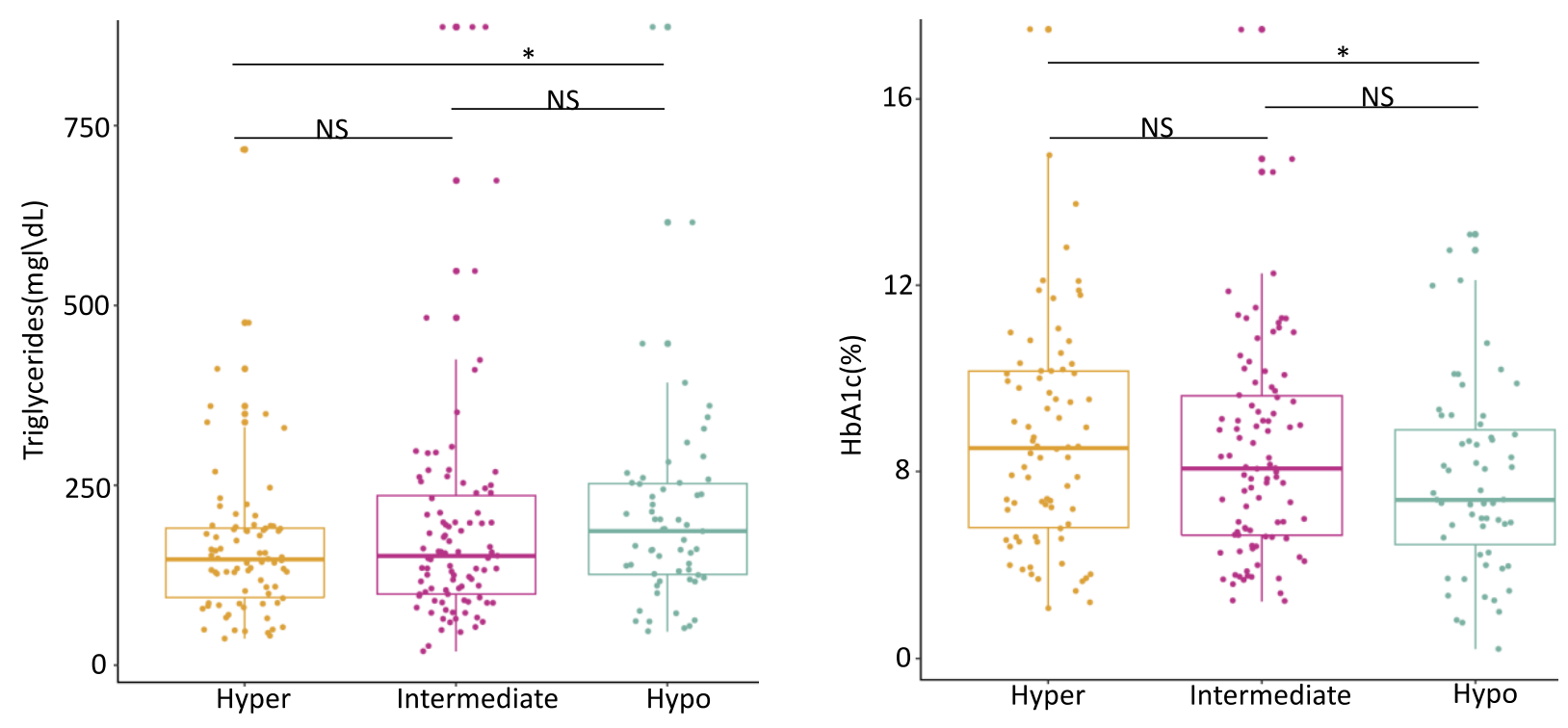

Figure 3: a. Heatmap showing clustering of T2DM patients using the methylation level of 14 hub $C p G$ sites. The analysis revealed three subgroups of T2DM patients with low, intermediate, and 
high methylation at the hub CpG sites. Boxplot showing the difference in (b)HDL level, (b)triglycerides, and (c) HbAlc between 3 patients' groups. The p-value has been calculated using the non-parametric Wilcox test.

\section{Discussion:}

T2DM has multiple risk factors (e.g., high-fat diet, genetic susceptibility), and many of them are prevalent at the population level $(4,5,6,7)$. Several of these factors can affect the disease risk through hypo- or hypermethylation of genes leading to alteration in specific gene expression $(11,12,13,18)$. To identify these differentially methylated $\mathrm{CpG}$ sites, we performed an EWAS in 844 Indian individuals of Indo-European origin and explored the possible mechanism of associations by integrating epigenome-based co-methylation network analysis and methQTL analysis. To the best of our knowledge, this is the first study that integrates EWAS with a comethylation study to identify DNA methylations that confer T2DM risk.

The current study identified a significant association of methylation in 3 known and 6 novel differentially methylated $\mathrm{CpG}$ sites with T2DM risk in Indian populations. We replicated hypomethylation of $\operatorname{cg} 19693031$ (in 3'UTR region of TXNIP) in T2DM cases like that of the nonresident Indian individuals in the London Life Sciences Prospective Population cohort (LOLIPOP) study (44). The association of cg19693031 methylation with T2DM risk has been replicated in the German (46), Caucasian (47), and Arab populations (48). As previously reported in Caucasian patients recruited in Spain, cg19693031 was also associated with sustained hyperglycemia (HbA1c) level in the Indian population (44). TXNIP is induced by higher glucose levels in pancreatic $\beta$-cell (49) and has been implicated in glucose-mediated apoptosis of $\beta$-cell death (50) in diabetes cases.

We also replicated hypermethylation of $\operatorname{cg} 11024682$ (SREBF1) as a risk factor for T2DM that was associated with incident diabetes in non-resident Indians in LOLIPOP cohort (44) and in the EPICNorfolk cohort (47). However, this signal failed to replicate in the Caucasian Botnia Cohort study (51) indicating a population-specific role towards T2DM risk. SREBF1, a transcription factor activated by $\mathrm{AKT} / \mathrm{mTOR}$ signaling is responsible for the transcription of fatty acid synthesis genes (52) indicating that it may affect T2DM etiology through lipid-metabolism-mediated pathways. We also replicated the association of $\operatorname{cg} 00574958$ in CPT1A in the Indian population. Cg00574958 associated with incident T2DM in The Framingham Heart Study, EPICNorfolk, and LOLIPOP cohort (47). Further methylation of $\operatorname{cg} 00574958$ has also found to be associated with T2DM in Qatari family study (48), with adiposity among Ghanaians (53), with cardiovascular risk in Registre Gironi del Cor (Girona Heart Registry) of Spanish population, as well as with hypertriglyceridemia and waist phenotype of Mexican family study (54). CPT1A encodes for carnitine palmitoyltransferase 1 that transports long-chain fatty acids into the mitochondria for oxidation and contributes to maintaining glucagon secretion from pancreatic 
islets (55). Further, prolonged inhibition of CPT1A leads to lipid accumulation and insulin resistance in muscle cells of rats (56).

We also identified cg16171771 (near PDCD6IP), cg16171771 (near MIR1287), and cg04673737 (near $\left.5 S \_r R N A\right)$ as EWAS signal for T2DM $\left(1.03 \times 10^{-11}\right)$ and are hypomethylated in the T2DM cases. Programmed cell death 6 interacting protein (PDCD6IP), is one of the most intensely studied multifunctional cytosolic and multi-domain scaffold proteins involved in multiple function including clathrin-mediated endocytosis, apoptosis, and also perform membrane repair (57). The gene may be involved in insulin secretion from pancreas via exocytosis. MIR 1287 is a microRNA that targets RAF1 which is involved in RAS-RAF-MEK-ERK pathways (58); hence, it may influence multiple metabolic process (e.g., glycolysis) relevant to T2DM physiology. MIR1287 was downregulated in symptomatic patients with carotid plaques undergoing carotid endarterectomy (59) suggesting its possible role in metabolic disorders. Identified gene 5S_rRNA is a ribosomal RNA found in mitochondria and believed to play an important role in assemblage of $5 \mathrm{~S}$ subunit of RNA. It has been also suggested to have role in translational efficiency of mitochondrial ribosome and has differential modifications in T2DM mouse model as compared to healthy control (60). However, the precise role of these genes in T2DM physiology is largely unknown.

Our study identified hypomethylation at the gene-body $\mathrm{CpG}(\operatorname{cg} 24458314)$ in HDAC9 as EWAS signal for T2DM. HDAC9 encodes for the histone deacetylase 9, and the knockdown of $H D A C 9$ protects from adipose tissue dysfunction and improves glucose tolerance as well as insulin sensitivity in high-fat-fed mice (61). However, the exact relation between cg24458314 methylation and its role in $H D A C 9$ expression in T2DM needs to be explored for further mechanistic insight. Inhibition of this gene induces insulin resistance and T2DM in the case of high diet-fed mouse $(61,62)$. We also identified cg15815318 in the RTN1 gene body as hypomethylated in diabetic patients. RTN1 codes for Reticulon 1 that is an established marker of chronic kidney disease and is highly expressed (63) in the kidneys of both human and murine models of HIV-associated nephropathy (HIVAN) as well as diabetic nephropathy. In vitro, RTN1A causes hyperglycemia and albumin-induced ER stress and death of both podocytes and renal tubular cells indicating that RTN1 is a key mediator for proteinuria-induced tubular cell toxicity and renal fibrosis in case of diabetic nephropathy (64). However, these signals need replication in other ethnic cohorts.

Additionally, we also identified cg23372795 site in KCNK16 (potassium two pore domain channel subfamily K member 16) gene, a known GWAS signal for T2DM involved in insulin secretion in pancreatic $\beta$-cell as differentially methylated at EWA significance level. KCNK16 induces $\beta$-cell membrane depolarization by increasing $\mathrm{Ca} 2+$ influx and tunes glucose-stimulated insulin secretion (65).

The comethylation network analysis in 264 controls revealed the presence of 4 methylated modules (turquoise, blue, brown, and yellow) among differentially methylated $\mathrm{CpG}$ sites that were preserved in independent datasets containing 254 T2DM cases suggesting a conserved comethylation interaction among this $\mathrm{CpG}$ sites across samples. Further, the group methylations (eigengene) of the brown and yellow modules were associated with T2DM associated risk traits (e.g., BMI, CpG sites were correlated with T2DM risk factors). Detailed analysis of brown module identified 14 hub CpG low methylation sites that can be used to identify a subgroup of T2DM 
patients with significantly low HDL, high triglycerides, high C-peptide, but with low HbA1c. These patient groups are dyslipidemic with good glycemic control, which is uncommon to the usual case of dyslipidemia and poor glycemic control observed in most of the T2DM cohorts. Methylation at these $14 \mathrm{CpG}$ sites can be used as prognostic markers to predict treatment outcome (e.g., lipid control, glycemic control) in patients, however these results need to be evaluated in a prospective cohort in the future.

Our analysis identified rs6503650 in the $J U P$ gene as a potential methylation QTL for all 14 hub $\mathrm{CpG}$ sites of the brown module, indicating that JUP may regulate the methylation of other hub genes. JUP codes for junction plakoglobin and is required for insulin-induced signaling and glucose uptake in adipocytes (66). Plakoglobin binding promotes PI3K-Akt-FoxO signaling and improves glucose uptake and insulin sensitivity in muscles (67). The eigengene of the brown module was associated with insulin and C-peptide level along with BMI. The identification of the JUP gene as a central regulator for the brown module and its role in glucose uptake and insulin sensitivity suggests that the brown module genes may regulate glucose uptake and insulin sensitivity in muscle. However, this finding needs to be confirmed through functional studies in animal model systems and larger prospective human cohorts.

We recognize several limitations in our study. The discovery phase results showed a higher inflation factor that could be led to false-positive results in the discovery phase. However, replication of the signal in an independent validation cohort confirms the association of replicated signals. This co-methylation network analysis aimed at identifying the interactions between CpG sites needs validation through functional studies in appropriate model systems (e.g., cell lines).

In conclusion, the current study replicated 3 loci and identified 6 novel, robust and consistent $\mathrm{CpG}$ sites with differential methylations implicated for T2DM risk at epigenome-wide significance level. These appear to be related to T2DM via glucose and obesity-related pathways that had their effects in a coordinated manner as observed from the co-methylation analysis.

\section{Conflict of interest and author contribution:}

AKG researched data, performed the experiment contributed to discussion, and wrote the manuscript. GP, VK, and DK helped in the data collection. NT helped in study participant recruitment. DB researched data, contributed to discussion, and reviewed and edited the manuscript. DB is the guarantor of this work and, as such, had full access to all the data in the study and takes responsibility for the integrity of the data and the accuracy of the data analysis. The authors declare no conflict of interest.

\section{Acknowledgments:}

This study was supported by CARDIOMED (BSC0122- 16) funded by the Council of Scientific and Industrial Research (CSIR), Government of India and University Potential of Excellence (UPOE II) from Jawaharlal Nehru University, New Delhi, India. The authors are thankful to all 
the participating subjects, their parents, and the school authorities for support and cooperation in carrying out the study. We thank Soham Bharadwaj for critically evaluating and editing the manuscript.

\section{References:}

1. International Diabetes Federation. IDF Diabetes Atlas - 9th Edition. DiabetesAtlas http://www. diabetesatlas.org/ (2017).

2. Zheng Y, Ley SH, Hu FB: Global aetiology and epidemiology of type 2 diabetes mellitus and its complications. Nature Reviews Endocrinology 2017; 14:88-98.

3. Knowler WC, Barrett-Connor E, Fowler SE, Hamman RF, Lachin JM, Walker EA, Nathan DM; Diabetes prevention program research group: reduction in the incidence of type 2 diabetes with lifestyle intervention or Metformin. New England Journal of Medicine 2002;346:393-403

4. Ley SH, Hamdy O, Mohan V, Hu FB: Prevention and management of type 2 diabetes: dietary components and nutritional strategies. The Lancet 2014;383:1999-2007

5. Sigal, R.J., Kenny, G.P., Wasserman, D.H., Castaneda-Sceppa, C., and White, R.D. (2006). Physical activity/exercise and type 2 diabetes: A consensus statement from the American Diabetes Association. Diabetes Care. 2006; 29:1433-1438.

6. Pan A, Wang Y, Talaei M, Hu FB, Wu T: Relation of active, passive, and quitting smoking with incident type 2 diabetes: a systematic review and meta-analysis. The Lancet Diabetes \& Endocrinology 2015;3:958-967

7. Knott C, Bell S, Britton A: Alcohol consumption and the risk of Type 2 Diabetes: A systematic review and dose-response meta-analysis of more than 1.9 million individuals from 38 observational studies. Diabetes Care 2015;38:1804-1812

8. Tsai P-C, Glastonbury CA, Eliot MN, Bollepalli S, Yet I, Castillo-Fernandez JE, CarneroMontoro E, Hardiman T, Martin TC, Vickers A, Mangino M, Ward K, Pietiläinen KH, Deloukas P, Spector TD, Viñuela A, Loucks EB, Ollikainen M, Kelsey KT, Small KS, Bell JT: Smoking induces coordinated DNA methylation and gene expression changes in adipose tissue with consequences for metabolic health. Clinical Epigenetics 2018;10

9. Giri AK, Banerjee P, Chakraborty S, Kauser Y, Undru A, Roy S, Parekatt V, Ghosh S, Tandon $\mathrm{N}$, Bharadwaj D: Genome wide association study of uric acid in Indian population and interaction of identified variants with Type 2 diabetes. Sci Rep 2016;6:21440

10. Nakanishi S, Shimoda M, Tatsumi F, Kohara K, Obata A, Katakura Y, Sanada J, Fushimi Y, Iwamoto Y, Onishi M, Isobe H, Kusano T, Dan K, Wamata R, Iwamoto H, Mune T, Kaku K, Kaneto H: Effects of sedentary behavior and daily walking steps on BMI and body composition: Prospective observational study using outpatient clinical data of Japanese patients with type 2 diabetes. Journal of Diabetes Investigation 2021;

11. Alvarez-Silva C, Kashani A, Hansen TH, Pinna NK, Anjana RM, Dutta A, Saxena S, Støy J, Kampmann U, Nielsen T, Jørgensen T, Gnanaprakash V, Gnanavadivel R, Sukumaran A, Rani CSS, Færch K, Radha V, Balasubramanyam M, Nair GB, Das B, Vestergaard H, Hansen T, Mande SS, Mohan V, Arumugam M, Pedersen O: Trans-ethnic gut microbiota signatures of type 2 diabetes in Denmark and India. Genome Medicine 2021;13 
12. Ling C, Rönn T: Epigenetics in human obesity and type 2 diabetes. Cell Metabolism 2019;29:1028-1044

13. Bramswig NC, Kaestner KH: Epigenetics and diabetes treatment: an unrealized promise? Trends Endocrinol Metab 2012;23:286-291

14. Greally JM, Rönn T, Volkov P, Davegårdh C, Dayeh T, Hall E, Olsson AH, Nilsson E, Tornberg Å, Dekker Nitert M, Eriksson K-F, Jones HA, Groop L, Ling C: A Six months exercise intervention influences the genome-wide DNA methylation pattern in human adipose tissue. PLoS Genetics 2013;9:e1003572

15. Yang BT, Dayeh TA, Volkov PA, Kirkpatrick CL, Malmgren S, Jing X, Renström E, Wollheim CB, Nitert MD, Ling C. Increased DNA methylation and decreased expression of PDX-1 in pancreatic islets from patients with type 2 diabetes. Mol Endocrinol. 2012 Jul;26(7):1203-12.

16. Macartney-Coxson D, Benton MC, Blick R, Stubbs RS, Hagan RD, Langston MA: Genomewide DNA methylation analysis reveals loci that distinguish different types of adipose tissue in obese individuals. Clin Epigenetics 2017;9:48

17. Ribel-Madsen R, Fraga MF, Jacobsen S, Bork-Jensen J, Lara E, Calvanese V, Fernandez AF, Friedrichsen M, Vind BF, Hojlund K, Beck-Nielsen H, Esteller M, Vaag A, Poulsen P: Genome-wide analysis of DNA methylation differences in muscle and fat from monozygotic twins discordant for type 2 diabetes. PLoS One 2012; 7:e51302

18. Marloes Dekker Nitert, Tasnim Dayeh, Peter Volkov, Targ Elgzyri, Elin Hall,Emma Nilsson, Beatrice T. Yang, Stefan Lang, Hemang Parikh, Ylva Wessman,Holger Weishaupt, Joanne Attema,Mia Abels, Nils Wierup, Peter Almgren, Per-Anders Jansson, Tina Rönn,Ola Hansson, Karl-Fredrik Eriksson, Leif Groop, and Charlotte Ling. Impact of an exercise intervention on DNA methylation in skeletal muscle from first-degree relatives of patients with type 2 diabetes. Diabetes. 2012 Dec; 61(12): 3322-3332.

19. Laird PW: Principles and challenges of genomewide DNA methylation analysis. Nat Rev Genet 2010;11:191-203

20. Breton CV, Marsit CJ, Faustman E, Nadeau K, Goodrich JM, Dolinoy DC, Herbstman J, Holland N, LaSalle JM, Schmidt R, Yousefi P, Perera F, Joubert BR, Wiemels J, Taylor M, Yang IV, Chen R, Hew KM, Freeland DMH, Miller R, Murphy SK: Small-magnitude effect sizes in epigenetic end points are important in children's environmental health studies: the children's environmental health and disease prevention research center's epigenetics working group. Environmental Health Perspectives 2017;125:511-526

21. Langfelder P, Horvath S: WGCNA: an R package for weighted correlation network analysis. BMC Bioinformatics 2008;9

22. Zhang X, Cui Y, Ding X, Liu S, Han B, Duan X, Zhang H, Sun T: Analysis of mRNA-lncRNA and mRNA-lncRNA-pathway co-expression networks based on WGCNA in developing pediatric sepsis. Bioengineered 2021;12:1457-1470 
23. Zhou J-G, Liang B, Liu J-G, Jin S-H, He S-S, Frey B, Gu N, Fietkau R, Hecht M, Ma H, Gaipl US: Identification of 15 lncRNAs Signature for predicting survival benefit of advanced melanoma patients treated with anti-PD-1 monotherapy. Cells 2021;10:977

24. Su Y, Zhang T, Tang J, Zhang L, Fan S, Zhou J, Liang C: Construction of competitive endogenous RNA network and verification of 3-key LncRNA signature associated with distant metastasis and poor prognosis in patients with clear cell renal cell carcinoma. Frontiers in Oncology 2021;11

25. INdian DIabetes Consortium INDICO: the development of a resource for epigenomic study of Indians undergoing socioeconomic transition. Hugo J. 2011 Dec; 5(1-4): 65-69.

26. Bandesh K, Prasad G, Giri AK, Kauser Y, Upadhyay M, Basu A, Tandon N, Bharadwaj D: Genome-wide association study of blood lipids in Indians confirms universality of established variants. Journal of Human Genetics 2019;64:573-587

27. Tabassum R, Chauhan G, Dwivedi OP, Mahajan A, Jaiswal A, Kaur I, Bandesh K, Singh T et al. Genome-wide association study for type 2 diabetes in Indians identifies a new susceptibility locus at 2q21. Diabetes. 2013 Mar;62(3):977-86.

28. Giri AK, Prasad G, Bandesh K, Parekatt V, Mahajan A, Banerjee P, Kauser Y, Chakraborty S, Rajashekar D, Sharma A, et al. Multifaceted genome-wide study identifies novel regulatory loci in SLC22A11 and ZNF45 for body mass index in Indians. Molecular Genetics and Genomics 2020; 295:1013-26.

29. Prasad G, Giri AK, Basu A, Tandon N, Bharadwaj D: Genomewide association study for Creactive protein in Indians replicates known associations of common variants. Journal of Genetics 2019;98.

30. Prasad G, Bandesh K, Giri A, Kauser Y, Chanda P, Parekatt V, Mathur S, Madhu S, Venkatesh P, Bhansali A, Marwaha R, Basu A, Tandon N, Bharadwaj D: Genome-wide association study of metabolic syndrome reveals primary genetic variants at CETP locus in Indians. Biomolecules 2019;9:321.

31. Giri AK, Tomar A, Ravindran A, Basu A, Tandon N, Bharadwaj D: DNA methylation profiling reveals the presence of population-specific signatures correlating with phenotypic characteristics. Molecular Genetics and Genomics 2017;292:655-662.

32. Giri AK, Aittokallio T: DNMT inhibitors increase methylation in the cancer genome. Frontiers in Pharmacology 2019;10.

33. Aryee MJ, Jaffe AE, Corrada-Bravo H, Ladd-Acosta C, Feinberg AP, Hansen KD, Irizarry RA: Minfi: a flexible and comprehensive Bioconductor package for the analysis of Infinium DNA methylation microarrays. Bioinformatics 2014;30:1363-1369

34. Chen YA, Lemire M, Choufani S, Butcher DT, Grafodatskaya D, Zanke BW, Gallinger S, Hudson TJ, Weksberg R: Discovery of cross-reactive probes and polymorphic CpG sites in the Illumina Infinium HumanMethylation450 microarray. Epigenetics 2013;8:203-209 
35. Teschendorff AE, Marabita F, Lechner M, Bartlett T, Tegner J, Gomez-Cabrero D, Beck S: A beta-mixture quantile normalization method for correcting probe design bias in Illumina Infinium 450 k DNA methylation data. Bioinformatics 2013;29:189-196

36. Houseman EA, Accomando WP, Koestler DC, Christensen BC, Marsit CJ, Nelson HH, Wiencke JK, Kelsey KT. DNA methylation arrays as surrogate measures of cell mixture distribution. BMC Bioinformatics. 2012 May 8;13:86.

37. Zou J, Lippert C, Heckerman D, Aryee M, Listgarten J. Epigenome-wide association studies without the need for cell-type composition. Nat Methods. 2014 Mar;11(3):309-11. doi: 10.1038/nmeth.2815. Epub 2014 Jan 26. PMID: 24464286.

38. Lehne B, Drong AW, Loh M, Zhang W, Scott WR, Tan ST, Afzal U, Scott J, Jarvelin MR, Elliott P, McCarthy MI, Kooner JS, Chambers JC: A coherent approach for analysis of the Illumina HumanMethylation450 BeadChip improves data quality and performance in epigenome-wide association studies. Genome Biol 2015;16:37

39. Suchiman HED, Slieker RC, Kremer D, Slagboom PE, Heijmans BT, Tobi EW: Design, measurement and processing of region-specific DNA methylation assays: the mass spectrometry-based method EpiTYPER. Frontiers in Genetics 2015;6

40. Balduzzi S, Rücker G, Schwarzer G: How to perform a meta-analysis with R: a practical tutorial. Evidence Based Mental Health 2019;22:153-160

41. Bharadwaj D, Dutta T, Giri AK, Khan MN, Tandon N, Nair SK.. Metabolic adaptation in Indians emigrated to USA-changes in DNA methylation and amino acid metabolites in comparison with Northern-European 2014 - AMER DIABETES ASSOC 1701 N, DIABETES, 2014

42. Shannon P, Markiel A, Ozier O, Baliga NS, Wang JT, Ramage D, Amin N, Schwikowski B, Ideker T: Cytoscape: a software environment for integrated models of biomolecular interaction networks. Genome Res 2003;13:2498-2504

43. Nogales-Cadenas R, Carmona-Saez P, Vazquez M, Vicente C, Yang X, Tirado F, Carazo JM, Pascual-Montano A: GeneCodis: interpreting gene lists through enrichment analysis and integration of diverse biological information. Nucleic Acids Research 2009;37:W317-W322.

44. Chambers JC, Loh M, Lehne B, Drong A, Kriebel J, Motta V, Wahl S, Elliott HR, Rota F, Scott WR, Zhang W, Tan S-T, Campanella G, Chadeau-Hyam M, Yengo L, Richmond RC, Adamowicz-Brice M, Afzal U, Bozaoglu K, Mok ZY, Ng HK, Pattou F, Prokisch H, Rozario MA, Tarantini L, Abbott J, Ala-Korpela M, Albetti B, Ammerpohl O, Bertazzi PA, Blancher C, Caiazzo R, Danesh J, Gaunt TR, de Lusignan S, Gieger C, Illig T, Jha S, Jones S, Jowett J, Kangas AJ, Kasturiratne A, Kato N, Kotea N, Kowlessur S, Pitkäniemi J, Punjabi P, Saleheen D, Schafmayer C, Soininen P, Tai ES, Thorand B, Tuomilehto J, Wickremasinghe AR, Kyrtopoulos SA, Aitman TJ, Herder C, Hampe J, Cauchi S, Relton CL, Froguel P, Soong R, Vineis P, Jarvelin M-R, Scott J, Grallert H, Bollati V, Elliott P, McCarthy MI, Kooner JS: Epigenome-wide association of DNA methylation markers in peripheral blood from Indian Asians and Europeans with incident type 2 diabetes: a nested case-control study. The Lancet Diabetes \& Endocrinology 2015;3:526-534 
45. Soriano-Tarraga C, Jimenez-Conde J, Giralt-Steinhauer E, Mola-Caminal M, VivancoHidalgo RM, Ois A, Rodriguez-Campello A, Cuadrado-Godia E, Sayols-Baixeras S, Elosua R, Roquer J, Consortium G: Epigenome-wide association study identifies TXNIP gene associated with type 2 diabetes mellitus and sustained hyperglycemia. Hum Mol Genet 2016;25:609-619

46. Florath I, Butterbach K, Heiss J, Bewerunge-Hudler M, Zhang Y, Schottker B, Brenner H: Type 2 diabetes and leucocyte DNA methylation: an epigenome-wide association study in over 1,500 older adults. Diabetologia 2016;59:130-138

47. Cardona A, Day FR, Perry JRB, Loh M, Chu AY, Lehne B, Paul DS, Lotta LA, Stewart ID, Kerrison ND, Scott RA, Khaw KT, Forouhi NG, Langenberg C, Liu C, Mendelson MM, Levy D, Beck S, Leslie RD, Dupuis J, Meigs JB, Kooner JS, Pihlajamaki J, Vaag A, Perfilyev A, Ling C, Hivert MF, Chambers JC, Wareham NJ, Ong KK: Epigenome-wide association study of incident type 2 diabetes in a British population: EPIC-Norfolk study. Diabetes 2019;68:2315-2326

48. Al Muftah WA, Al-Shafai M, Zaghlool SB, Visconti A, Tsai PC, Kumar P, Spector T, Bell J, Falchi M, Suhre K: Epigenetic associations of type 2 diabetes and BMI in an Arab population. Clin Epigenetics 2016;8:13

49. Shalev A: Minireview: Thioredoxin-interacting protein: regulation and function in the pancreatic beta-cell. Mol Endocrinol 2014;28:1211-1220

50. Chen J, Saxena G, Mungrue IN, Lusis AJ, Shalev A: Thioredoxin-interacting protein: a critical link between glucose toxicity and beta-cell apoptosis. Diabetes 2008;57:938-944

51. Dayeh T, Tuomi T, Almgren P, Perfilyev A, Jansson PA, de Mello VD, Pihlajamaki J, Vaag A, Groop L, Nilsson E, Ling C: DNA methylation of loci within ABCG1 and PHOSPHO1 in blood DNA is associated with future type 2 diabetes risk. Epigenetics 2016;11:482-488

52. Ye J, DeBose-Boyd RA: Regulation of cholesterol and fatty acid synthesis. Cold Spring Harb Perspect Biol 2011 Jul 1;3(7):a004754.

53. Meeks KAC, Henneman P, Venema A, Burr T, Galbete C, Danquah I, Schulze MB, Mockenhaupt FP, Owusu-Dabo E, Rotimi CN, Addo J, Smeeth L, Bahendeka S, Spranger J, Mannens M, Zafarmand MH, Agyemang C, Adeyemo A: An epigenome-wide association study in whole blood of measures of adiposity among Ghanaians: the RODAM study. Clin Epigenetics 2017;9:103

54. Mamtani M, Kulkarni H, Dyer TD, Goring HH, Neary JL, Cole SA, Kent JW, Kumar S, Glahn DC, Mahaney MC, Comuzzie AG, Almasy L, Curran JE, Duggirala R, Blangero J, Carless MA: Genome- and epigenome-wide association study of hypertriglyceridemic waist in Mexican American families. Clin Epigenetics 2016;8:6

55. Briant LJB, Dodd MS, Chibalina MV, Rorsman NJG, Johnson PRV, Carmeliet P, Rorsman P, Knudsen JG: CPT1a-Dependent Long-Chain Fatty Acid Oxidation Contributes to Maintaining Glucagon Secretion from Pancreatic Islets. Cell Rep 2018;23:3300-3311 
56. Dobbins RL, Szczepaniak LS, Bentley B, Esser V, Myhill J, McGarry JD: Prolonged inhibition of muscle carnitine palmitoyltransferase-1 promotes intramyocellular lipid accumulation and insulin resistance in rats. Diabetes 2001;50:123-130

57. Hurley JH, Odorizzi G: Get on the exosome bus with ALIX. Nat Cell Biol 2012;14:654-655

58. Zhang B, Li F, Zhu Z, Ding A, Luo J: CircRNA CDR1as/miR-1287/Raf1 Axis Modulates Hepatocellular Carcinoma Progression Through MEK/ERK Pathway. Cancer Manag Res 2020;12:8951-8964

59. Caparosa EM, Sedgewick AJ, Zenonos G, Zhao Y, Carlisle DL, Stefaneanu L, Jankowitz BT, Gardner P, Chang YF, Lariviere WR, LaFramboise WA, Benos PV, Friedlander RM:

Regional Molecular Signature of the Symptomatic Atherosclerotic Carotid Plaque. Neurosurgery 2019;85:E284-E293

60. Yan M, Wang Y, Hu Y, Feng Y, Dai C, Wu J, Wu D, Zhang F, Zhai Q: A high-throughput quantitative approach reveals more small RNA modifications in mouse liver and their correlation with diabetes. Anal Chem 2013;85:12173-12181

61. Chatterjee TK, Basford JE, Knoll E, Tong WS, Blanco V, Blomkalns AL, Rudich S, Lentsch AB, Hui DY, Weintraub NL. HDAC9 knockout mice are protected from adipose tissue dysfunction and systemic metabolic disease during high-fat feeding. Diabetes. 2014 Jan;63(1):176-87.

62. Chen Y, Du J, Zhao YT, Zhang L, Lv G, Zhuang S, Qin G, Zhao TC: Histone deacetylase (HDAC) inhibition improves myocardial function and prevents cardiac remodeling in diabetic mice. Cardiovasc Diabetol 2015;14:99

63. Xiao W, Fan Y, Wang N, Chuang PY, Lee K, He JC: Knockdown of RTN1A attenuates ER stress and kidney injury in albumin overload-induced nephropathy. Am J Physiol Renal Physiol 2016;310:F409-415

64. Fan Y, Xiao W, Li Z, Li X, Chuang PY, Jim B, Zhang W, Wei C, Wang N, Jia W, Xiong H, Lee K, He JC: RTN1 mediates progression of kidney disease by inducing ER stress. Nat Commun 2015;6:7841

65. Vierra NC, Dadi PK, Jeong I, Dickerson M, Powell DR, Jacobson DA: Type 2 diabetesassociated $\mathrm{K}+$ channel TALK-1 modulates beta-cell electrical excitability, second-phase insulin secretion, and glucose homeostasis. Diabetes 2015;64:3818-3828

66. Negoita F, Vavakova M, Säll J, Laurencikiene J, Göransson O: JUP/plakoglobin is regulated by salt-inducible kinase 2 , and is required for insulin-induced signaling and glucose uptake in adipocytes. Cellular Signalling 2020;76:109786.

67. Cohen S, Lee D, Zhai B, Gygi SP, Goldberg AL. Trim32 reduces PI3K-Akt-FoxO signaling in muscle atrophy by promoting plakoglobin-PI3K dissociation. J Cell Biol. 2014 Mar $3 ; 204(5): 747-58$. 